\title{
Instructing Patrons in OCLC in an Academic Library
}

Editor's Note: This report is hased on a presentation at the 1982 Amnual Conference of the Illinois Library Association.

Because of its early emphasis on cataloging, OCLC remained out of the patron's reach until the mid-1970s. But as the database grew larger and more reliable, patron service implications grew along with it.

The importance of OCLC in locating material was obvious for interlibrary loan applications even before that subsystem was implemented in 1979 . Several years earlier. OCLC public access terminals had been made available on a trial basis at a number of institutions. Because automated circulation systems had been in existence since the $1960 \mathrm{~s}$ and various public access terminals were already in use, OCLC terminals often were installed in environments $w$ here patrons were accustomed to computer terminals.

At institutions in Illinois using the Library Computer System (LCS). patrons can use terminals to check holdings and their availability in local collections. They may also check other collections to which they have access. If at this point their needs are still unsatisfied, they are then ready to use OCLC to search for other locations.

Training patrons to use OCLC has several obvious advantages. It increases their awareness of the library's resource-sharing services; it introduces them to an important bibliographic tool: and it encourages them to provide citations for interlibrary loan that are complete and accurate.

To be most effective any instructional program should be accompanied by appropriate publicity, printed instructions, and a program evaluation. Announcements of the training can be made through campus publications or mailings and posted in the library on OCLC terminals. on public access terminals for the local circulation system, and at the site of the National Union Catalog volumes.

Printed instructions of varying complexity can be provided at the terminal itself. At the most detailed level. OCLC publications such as Searching the On-Line Union Catalog and "OCLC Participating Institutions-Arranged by OCLC Symbol" are particularly helpful. For most patrons, brief instructions that can be carried away are more practical. At the University of Illinois at Chicago, for example, a one-page, legal-sized sheet. "Using the OCLC Catalog," has been developed. It shows the kerboard and screen with annotations: how to search by author, title, and author/title; how to find locations: and brief information about the OCLC database. A supply is kept next to the terminal.

For patrons who have learned to use the system, brief prompts are all that is necessary. These can be scotch-taped directly onto the terminal. They need to show the number of characters and commas required for formulating the search codes. It is also helpful to include OCLC symbols of other libraries used bi your patrons. If they have reciprocal borrowing privileges, they may go directly to the holding library.

Although truly online instructions are not available, OCLC does have some prompts in its displays. There is also a test record, OCLC \#2865895, which describes the various fields of the OCLC MARC format.

The instructional program most effective is point-of-use instruction; formal demonstrations out of context are in general not remembered by patrons. At UIC. instruction is scheduled for two hours a day for two weeks each çuarter. Dates and times were chosen to coincide with a similar but more extensive program for the Library Computer System. LCS demonstrators refer patrons to OCLC as a logical extension beyond LCS. Demonstrations for both programs are given by volunteers from all departments in the library. Assistance is always available and individual appointments can also be arranged outside the scheduled instruction times.

Although there has been no written evaluation solicited from our patrons, their verbal comments are al ways positive. On the basis of these comments and an increase in patron use, the program and the printed instructions have been judged successful.-Robert A. Daugherty.

Robert A. Daugherty is circulation librarian at the Unicersity of Illinois at Chirago.

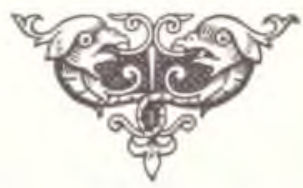

February $1983 / 35$ 